\title{
Quality of life among postmenopausal women in rural Minia, Egypt
}

Nashwa N. Kamal ${ }^{7}$ and Amany E. Seedhom ${ }^{7}$

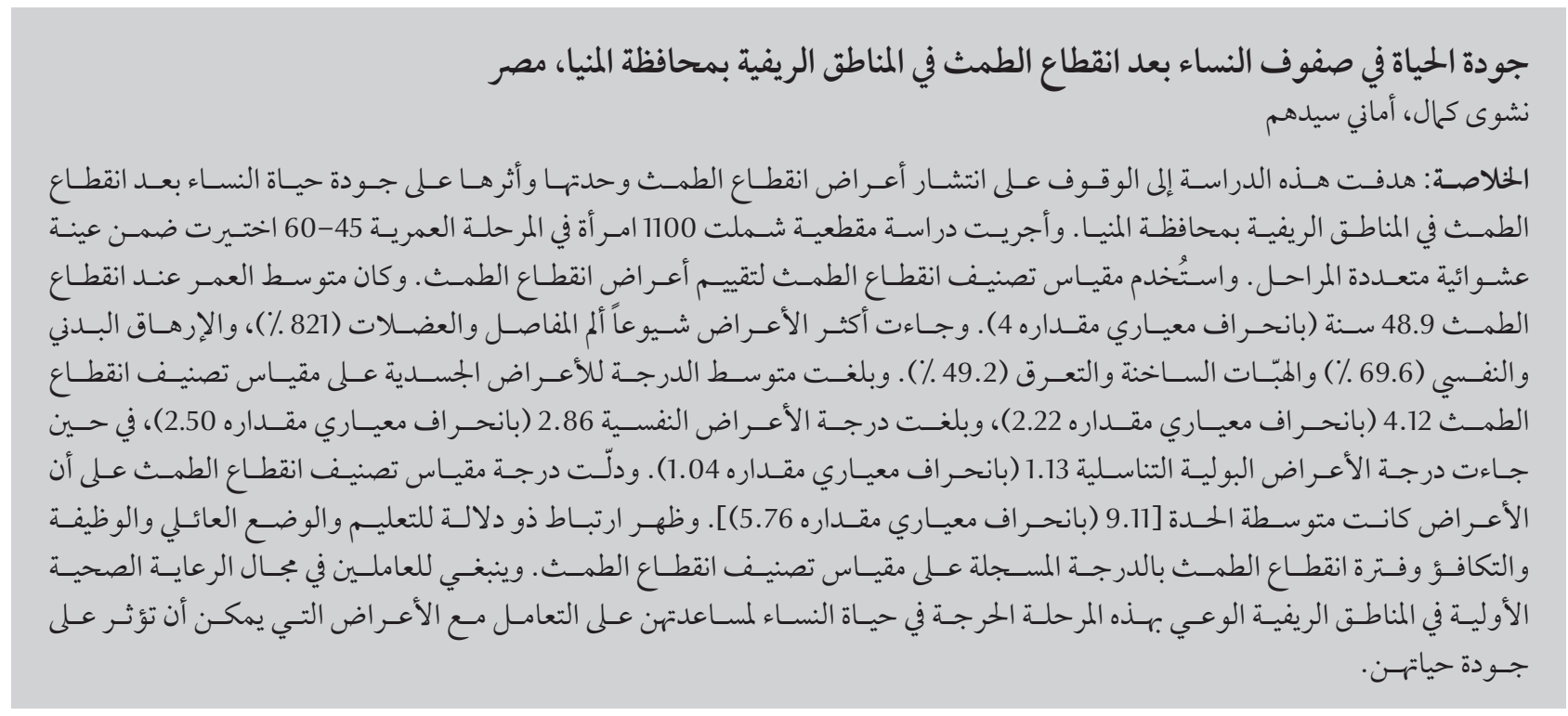

ABSTRACT This study aimed to determine the prevalence and severity of menopausal symptoms and their effect on the quality of life of postmenopausal women in rural Minia. A cross-sectional study was conducted among 1100 postmenopausal women aged 45-60 years selected by multistage random sampling. The menopause rating scale (MRS) was used to assess the menopausal symptoms. The mean age at menopause was 48.9 (SD 4) years. The most frequent symptoms were joint and muscle pain (82.1\%), physical and mental exhaustion (69.6\%) and hot flushes and sweating (49.2\%). The mean MRS somatic score was 4.12 (SD 2.22), the psychological score was 2.86 (SD 2.50) and urogenital score was 2.13 (SD 1.04). The total MRS score indicated that the symptoms were of moderate severity [9.11 (SD 5.76)]. Education, marital status, occupation, parity and postmenopausal duration were significantly associated with MRS score. Rural primary health care workers should be aware of this critical stage of life in women to help women deal with symptoms that may affect their quality of life.

\section{Qualité de vie parmi les femmes ménopausées dans les zones rurales du gouvernorat de Minya (Égypte)}

RÉSUMÉ La présente étude avait pour objectif de déterminer la prévalence et la sévérité des symptômes de la ménopause ainsi que leur impact sur la qualité de vie des femmes ménopausées dans les zones rurales du gouvernorat de Minya. Une étude transversale a été menée auprès de 1100 femmes ménopausées âgées de 45 à 60 ans sélectionnées par échantillonnage aléatoire à plusieurs degrés. L'échelle MRS (menopause rating scale) a été utilisée pour évaluer les symptômes de la ménopause. L'âge moyen à la ménopause était 48,9 ans (ET 4) . Les symptômes les plus fréquents étaient les douleurs articulaires et musculaires (82,1\%), l'épuisement physique et mental (69,6\%) ainsi que les bouffées de chaleur et la transpiration (49,2\%). Le score moyen de l'échelle MRS au niveau somatique était de 4,12 (ET 2,22) tandis qu'au niveau psychologique, il était de 2,86 (ET 2,50) et au niveau urogénital, de 2,13 (ET 1,04). Le score total indiquait une sévérité modérée des symptômes [9,11 (ET 5,76)]. L'éducation, la situation matrimoniale, l'emploi, la parité et la durée postménopause étaient significativement associés au score de l'échelle MRS. Les agents de soins de santé primaires ruraux doivent être conscients de cette étape critique de la vie des femmes afin de les aider à gérer les symptômes qui peuvent affecter la qualité de leur vie.

'Department of Public Health, Faculty of Medicine, Minia University, Minia, Egypt (Correspondence to: Nashwa N. Kamal: nashwakamal@yahoo. com). 


\section{Introduction}

Today, women can spend over one third of their life in the postmenopausal period. Women may experience compromised physical well-being during menopause and climacteric symptoms, such as vaginal dryness, hot flushes, sweats, and emotional changes (irritability, anxiety, mood changes, lack of concentration, difficulty with memory and insomnia).

Many factors can affect the experience of menopausal symptoms, including sociodemographic characteristics, cultural, psychosocial and lifestyle factors $(1,2)$. There is a considerable variation in the reporting of menopausal symptoms by women across the world. In Latin America, the most reported symptoms include hot flushes (68.9\%) followed by sleep disturbances (68.4\%) (3). In Australia, menopause was associated mostly with hot flushes, followed by night sweats (4). In Nigeria, joint and muscular discomfort were the most commonly reported symptom (59\%) (5). In Egypt, one study found the most common symptoms were fatigue followed by headache (6). Another study in Egypt reported that the most prevalent postmenopausal symptoms were joint pain (90.3\%), sleep problems $(84.0 \%)$ and physical and mental exhaustion (80.0\%) (7). Women from countries in East and South-east Asia reported joint and muscle pain as the most frequent complaint $(8,9)$.

The changes associated with menopause can affect a woman's quality of life (QOL). About $50-80 \%$ of women complain of menopausal symptoms such as hot flushes, night sweats, sleep disturbances, tiredness and depression. They are the main determinants of a reduced health-related QOL (10). Menopause-related symptoms can have a negative impact on the QOL of perimenopausal women (11). Postmenopausal women have a higher prevalence of menopausal symptoms that significantly affect their QOL than pre- and perimenopausal women (12).

The menopause rating scale (MRS) is a health-related QOL scale that was developed in the early 1990s and is a standardized scale with robust psychometric characteristics (13). The severity of menopausal symptoms, as measured using the MRS, is reported to reflect the profile of the QOL dimensions of the Short-Form-36; it can, therefore, be used to measure the QOL of postmenopausal women (1).

To date, there is limited information about menopause and QOL in developing countries and there are no published studies about menopausal symptoms and QOL in Minia (an Upper Egyptian governorate located about $245 \mathrm{~km}$ south of Cairo, the capital of Egypt).

The aim of the study therefore was to determine: 1) the prevalence and severity of menopausal symptoms and some of the influencing factors among Egyptian women in rural Minia, and 2) how menopausal symptoms affect their QOL. Rural women were chosen because they are generally of low socioeconomic status and are more likely to encounter financial problems, have poor access to health care, be unemployed or underemployed, face discrimination and lack education. The findings could be a guide for better planning of educational and counselling programmes to improve the QOL of postmenopausal women.

\section{Methods}

\section{Study design and sample}

This was a cross-sectional communitybased study conducted in a rural area in Minia governorate. The study was conducted from June to August 2015.

A multistage random sampling technique was used by means of a random number table. Minia governorate has 9 districts from which Minia district was chosen randomly. Minia district has 56 villages from which Demsheer village was chosen randomly using a random number table.

The inclusion criteria for the target population were: postmenopausal women aged $45-60$ years. (The WHO definition was used to define postmenopausal status in this study - permanent cessation of menses for 12 months from the last menstrual cycle that is not associated with a pathological cause) (14). Women with early menopause (younger than 45 years) or premature menopause (younger than 40 years), women with medically or surgically induced menopause, women who used hormone replacement therapy, and pregnant or lactating women were excluded.

The sample size was determined using Epi Info 2000 based on the population of Minia (4 000 000), a 50\% prevalence of postmenopausal symptoms and a 99\% confidence interval. This gave a sample size of 1100 women.

The first home (number 14) was chosen randomly. After this every 3rd house in number was selected. All eligible women were included in the study until the sample size was reached.

\section{Data collection}

For those who agreed to participate in the study, we immediately collected the information in a face-to-face interview in a private room. The interviews were conducted at 09:00-12:00 and at 17:00-19:00. Each interview lasted 5-10 minutes and data were collected using a predesigned questionnaire.

The questionnaire was developed after searching the literature for similar studies, taking into account the study objectives. It had 4 parts: sociodemographic data (age, marital status, educational background, occupation and parity); menstrual history (menopausal status, age at menopause); lifestyle factors (physical activity); and the MRS.

Exercise was defined as any physical activity, such as walking and domestic 
activities, for a duration of 20-30 minutes. It was divided into 3 levels: infrequent (less than 3 times/week), average (3-5 times/week) and more frequent (more than 5 times/week). In addition, weight and height were measured using stadiometer and an electronic weighing scaled to the nearest $0.1 \mathrm{~kg}$ and $0.5 \mathrm{~cm}$ respectively. Weight and height were measured in light clothing and without shoes. The body mass index (BMI) was calculated.

An Arabic version of the MRS, validated in a previous Egyptian study, was used (7). A few statements were changed in the Arabic translation to reflect the same meaning in the English version without affecting the results. To determine the reliability of the scale, a pilot study was conducted among 30 women in the study population (Cronbach alpha $=0.86$ ).

The MRS consists of 11 items assessing menopausal symptoms which are divided into 3 subscales: somatic, psychological and urogenital $(1,13,15)$.

Somatic symptoms include hot flushes, heart discomfort, sleeping problem and muscle and joint pain (items $1-3$ and 11 respectively). Psychological symptoms include depressive mood, irritability, anxiety, and physical and mental exhaustion (items 4-7 respectively). Urogenital symptoms include sexual problems, bladder problems and dryness of vagina (items 8-10 respectively). Each item is graded by the respondent from 0 (not present) to 4 (1 $=$ mild, $2=$ moderate, $3=$ severe, $4=$ very severe). The total score of each subscale is the sum of item scores contained in that subscale. The higher the score, the worse the QOL.

Total severity score ranged as follows: no or few symptoms (0-4), mild (4-8), moderate (916), and severe (7). We asked about the severity of symptoms by the degree of tolerability of symptoms, whether these symptoms affected their daily activities or if they had to take medication.

\section{Statistical analysis}

Data were analysed using SPSS, version 22. Analysis of variance tests were used to compare the means of the total MRS score and the somatic, psychological and urogenital subscale scores for postmenopausal women, exercise and BMI. Regression analysis was used with MRS scores as the dependent variables to determine predictors of MRS score and its subscales. A $P$-value $<0.05$ was considered statistically significant.

\section{Ethical considerations}

This study was approved by the research ethics committee of Minia University. All procedures performed were in accordance with the ethical standards of the institutional research ethics committee. Verbal consent was obtained from each participant and all data were kept confidential and used for research purposes only (full names, full date of birth, address and telephone number).

\section{Results}

\section{Response rate}

Only 3 women declined to participate and we replaced them with another 3 women chosen by selecting 3 more houses in the same pattern (every 3rd house).

\section{Sociodemographic characteristics of the studied women}

The study included 1100 postmenopausal women aged 45-60 years with a mean age [standard deviation (SD)] of 50.2 (SD 2.6) years. Table 1 shows the socioeconomic characteristics of the participants. Most women were married (88.8\%), 59.6\% were illiterate, $86.7 \%$ were housewives and $91.6 \%$ were parous. With regard to BMI and exercise, $43.3 \%$ of the women were overweight, while $35.6 \%$ were of normal weight, and $96.0 \%$ exercised $<3$ times / week. The mean age at menopause was
48.9 (SD 4) years with a median of 49.5 years (Table 1).

\section{Menopausal symptoms experienced}

The 3 most common symptoms reported were joint and muscle pain ( $82.1 \%)$, physical and mental exhaustion (69.6\%), and hot flushes and sweating (49.2\%) (Table 2). Of those who reported muscle and joint discomfort, more than half (53.6\%) considered it to be moderate to very severe. Of those who reported physical and mental exhaustion, $29.7 \%$ considered it to be moderate to very severe, while $31.2 \%$ of those with hot flushes and sweating considered the discomfort as moderate to very severe (Table 2 ).

\section{Quality of life}

The mean total score and subscale scores of the MRS are shown in Table 3. The mean total score was 9.11 (SD 5.76) and the somatic subscale was the largest component, 4.12 (SD 2.22).

\section{Effect of exercise and BMI on MRS score}

Women who exercised on average 3-5 times/week had a significantly lower total score and somatic score than those who exercised less frequently $(<3$ times/week) or more frequently $(>5$ times/week $)(P=0.01$ and $P=0.001$ respectively) (Table 3$)$.

Women with a normal BMI had a significantly lower total score $(P=$ $0.001)$ compared with underweight, overweight or obese women. Moreover, somatic and psychological subscale scores were significantly lower in women with normal BMI $(P=0.001, P$ $=0.006$ respectively) (Table 3 ).

\section{Factors affecting MRS scores}

All of the variables were entered in the multiple linear regression analysis (Table 4). Educational level and then parity and marital status made significant contributions to predicting the somatic score. Marital status, followed 


\begin{tabular}{|c|c|}
\hline Sociodemographic characteristic & No. $(\%)(n=1100)$ \\
\hline Age (years) [mean (SD)] & $50.2(2.6)$ \\
\hline \multicolumn{2}{|l|}{ Educational level } \\
\hline Illiterate & $656(59.6)$ \\
\hline Read and write & $298(27.1)$ \\
\hline High school and below & $112(10.2)$ \\
\hline University and above & $34(3.1)$ \\
\hline \multicolumn{2}{|l|}{ Occupation } \\
\hline Housewife & $954(86.7)$ \\
\hline Working outside the home & $130(11.8)$ \\
\hline Retired & $16(1.5)$ \\
\hline \multicolumn{2}{|l|}{ Marital status } \\
\hline Single & $28(2.6)$ \\
\hline Married & $977(88.8)$ \\
\hline Widowed/separated & $95(8.6)$ \\
\hline \multicolumn{2}{|l|}{ Parity } \\
\hline Parous & 1008 (91.6) \\
\hline Nulliparous & $92(8.4)$ \\
\hline Age at menopause (years) [mean (SD)] & $48.9(4)$ \\
\hline \multicolumn{2}{|l|}{ Exercise (times/week) } \\
\hline$<3$ & $1056(96.0)$ \\
\hline $3-$ & $38(3.5)$ \\
\hline$>10$ & $6(0.5)$ \\
\hline \multicolumn{2}{|l|}{ Body mass index } \\
\hline Underweight & $38(3.5)$ \\
\hline Normal weight & $392(35.6)$ \\
\hline Overweight & $476(43.3)$ \\
\hline Obese & $194(17.6)$ \\
\hline
\end{tabular}

by occupational status and then parity and age made significant contributions to predicting the psychological score. Educational level and then marital status, postmenopausal duration and parity made significant contributions to predicting the urogenital score. Postmenopausal duration followed by marital status, education, parity and then occupational status made significant contributions to predicting the total MRS score. These sociodemographic factors explained 51\%, 54\%, 59\% and $57 \%$ of the occurrence of somatic, psychological, urogenital and MRS symptoms respectively.

\section{Discussion}

In this study, the average age at natural menopause was 48.9 (SD 4) years with a median of 49.5 years. It is slightly higher than a study in Benham city, Egypt in 2010, which found the mean age at the menopause was 46.35 (SD 4.8) years (15), while it is lower than a study in Cairo which found a mean age at menopause of 49.2 years (7). However, it is lower than many countries (16).

The mean MRS total score was 9.11 (SD 5.76), which indicates there were moderate menopausal symptoms among the studied women (17), which

\begin{tabular}{lcc}
\hline \multicolumn{2}{l}{ Table 2 Prevalence of menopausal symptoms according to menopause rating scale among the postmenopausal women } \\
\hline Menopausal symptom & \% with symptoms $(\boldsymbol{n}=\mathbf{1 1 0 0})$ & \% with moderate to very severe symptoms ${ }^{\mathbf{a}}$ \\
Hot flush, sweating & 49.2 & 31.2 \\
Heart discomfort & 33.4 & 9.1 \\
Sleep problems & 22.1 & 11.2 \\
Joint, muscular discomforts & 82.1 & 53.6 \\
Depressed mood & 30.4 & 13.1 \\
Irritability & 23.5 & 11.3 \\
Anxiety & 30.3 & 10.6 \\
Physical, mental exhaustion & 69.6 & 29.7 \\
Sexual problems & 19.8 & 10.4 \\
Bladder problems & 32.1 & 13.1 \\
Vaginal dryness & 33.2 & 15.1 \\
\hline
\end{tabular}

aPercentage of those reporting having the symptom. 


\begin{tabular}{|c|c|c|c|c|}
\hline \multirow[t]{2}{*}{ Item } & \multicolumn{4}{|c|}{ Menopause rating scale [Mean (SD)] } \\
\hline & Somatic & Psychological & Urogenital & Total score \\
\hline Subscale scores & $4.12(2.22)$ & $2.86(2.50)$ & $2.13(1.04)$ & $9.11(5.76)$ \\
\hline \multicolumn{5}{|c|}{ Exercise (times/week) } \\
\hline$<3$ & $3.01(2.61)$ & $2.81(2.49)$ & $2.67(1.98)$ & $8.49(7.08)$ \\
\hline $3-5$ & $2.15(1.76)$ & $2.23(1.9)$ & $2.42(2.09)$ & $6.8(5.75)$ \\
\hline$>5$ & $5.12(2.23)$ & $2.32(1.89)$ & $2.17(2.35)$ & $9.61(6.47)$ \\
\hline$P$-value & 0.001 & 0.34 & 0.45 & 0.01 \\
\hline \multicolumn{5}{|l|}{ Body mass index } \\
\hline Underweight & $5.7(6.23)$ & $6.8(7.45)$ & $1.21(1.54)$ & $13.71(15.22)$ \\
\hline Normal weight & $2.56(2.01)$ & $1.45(1.63)$ & $1.45(1.82)$ & $5.46(5.46)$ \\
\hline Overweight & $4.32(2.3)$ & $3.12(2.67)$ & $1.73(1.76)$ & $9.17(6.73)$ \\
\hline Obese & $4.22(2.61)$ & $2.81(2.45)$ & $1.26(1.77)$ & $8.29(6.83)$ \\
\hline P-value & 0.001 & 0.006 & 0.1 & 0.001 \\
\hline
\end{tabular}

$S D=$ standard deviation.

is in line with a previous study in Ecuador which found a mean total MRS score of 9.1 (SD 6.4) (18).

The individual response to menopause and estrogen deficiency varies considerably due to genetic, cultural, lifestyle, socioeconomic, education and dietary factors (19). Our study showed that the most frequently reported menopausal symptoms were joint and muscular discomfort (82.1\%), physical and mental exhaustion (69.6\%) and hot flushes (53.6\%). This is consistent with another study which found that $80.1 \%$ of women reported joint and muscular discomfort as the most common symptom, followed by fatigue and stress (20). In addition, a study conducted in 2009 reported that joint and muscle discomfort, physical and mental exhaustion, and hot flushes were the most prevalent menopausal symptoms (21). However, a study in 2010 contradicts our results; in that study, vasomotor symptoms, such as hot flushes and night sweats, were the most frequently reported symptoms (22). These differences in frequencies of symptoms may be due to different lifestyles, physical housework, culture, genetic factors and diet.

Physical activity has been shown also to enhance QOL among menopausal women and some studies suggest that physical activity is associated with a decrease in hot flushes (23). In our study, women who performed domestic activities on average 3-5 times/week had a lower MRS score than those who did not. This agrees with another study that suggested that a high total physical activity level was associated with fewer menopausal symptoms (24).

Women with BMI scores in the normal range had lower vasomotor symptom scores and better health-related QOL scores than obese women, and those who gained weight were more likely to report deterioration in their QOL (25). We found that women with a normal BMI had a significantly lower total MRS score compared with underweight, overweight or obese women and this is consistent with another previous study (26). The association between

\begin{tabular}{|c|c|c|c|c|c|c|c|c|}
\hline \multirow{3}{*}{$\begin{array}{l}\text { Sociodemographic } \\
\text { characteristics }\end{array}$} & \multicolumn{8}{|c|}{ Menopause rating scale } \\
\hline & \multicolumn{2}{|c|}{ Somatic } & \multicolumn{2}{|c|}{ Psychological } & \multicolumn{2}{|c|}{ Urogenital } & \multicolumn{2}{|c|}{ Total score } \\
\hline & B & $P$-value & B & P-value & B & $P$-value & B & $P$-value \\
\hline Age & -0.015 & 0.09 & -0.006 & 0.03 & 0.034 & 0.9 & -0.022 & 0.1 \\
\hline Educational level & -0.148 & 0.03 & -0.015 & 0.08 & -0.185 & 0.03 & -0.142 & 0.003 \\
\hline Marital status & 0.082 & 0.01 & 0.155 & 0.04 & 0.124 & 0.002 & 0.155 & 0.03 \\
\hline Occupation & -0.017 & 0.2 & -0.075 & 0.01 & -0.085 & 0.06 & -0.056 & 0.02 \\
\hline Parity & -0.100 & 0.02 & -0.021 & 0.001 & -0.084 & 0.02 & -0.088 & 0.001 \\
\hline Postmenopause duration & -0.292 & 0.1 & -0.241 & 0.1 & -0.123 & 0.003 & -0.257 & 0.002 \\
\hline$R^{2}$ & \multicolumn{2}{|c|}{0.51} & \multicolumn{2}{|c|}{0.54} & \multicolumn{2}{|c|}{0.59} & \multicolumn{2}{|c|}{0.57} \\
\hline
\end{tabular}


obesity and vasomotor symptoms is contradictory. Peripheral conversion of androstenedione to estrone in adipose tissue is greater in obese postmenopausal women than women of normal weight and this might be associated with fewer hot flushes in overweight women. However, higher BMI correlated with a higher climacteric symptom score and this might be because overweight women sweat more frequently due to their extra weight and because obesity is also associated with less exercise and poorer general health (27).

Our study found that women of higher educational levels had lower MRS scores and this agrees with another previous study (28). Women who have higher education have greater access to information resources so they have better knowledge which may affect their QOL. Another study found that higher education usually resulted in higher income and more opportunities in career and social life and these women had greater access to health services, had more knowledge and benefited from more medical counselling (29). However, some studies did not find a relationship between the QOL and education in postmenopausal women (30).

Our results indicated that married women had a better QOL than unmarried and divorced/separated/widowed women. Many studies have shown that married menopausal women had more positive attitudes than unmarried and divorced/separated/widowed menopausal women and enjoyed a better QOL (31). This can be explained by the fact that married women may have greater social support and income and because they have a normal sex life and are mothers.

Occupational status was significantly correlated with the QOL in our study. Working women had a better QOL than housewives. Most studies confirm this association $(32,33)$. However, in another study, there was no association between the QOL of postmenopausal women and their occupational status (34). Having a job may increase the confidence in middle-aged women and help to improve their QOL.

In our study, there was an association between parity and the QOL. Nulliparity is associated with early onset of menopause (35) and parous women have an anovulatory period that delays the menopause.

There are some limitations in our study. All the participants were from one village, but we chose both the district (Minia) and the village (Demsheer) randomly so our results can be generalized to other villages in Minia. This was a cross-sectional study so it does not exclude confounding effects of the natural ageing process that may influence the experience of symptoms. In addition, the MRS is a self-completing questionnaire; however, knowing there would likely be a substantial number of the studied women who did not have formal education (in fact over half were illiterate), we used interviews instead in order to include them. In collecting data, women were asked to provide some retrospective information, such as menopausal symptoms experienced in the preceding 1 month, last menstruation, etc. Hence recall bias was unavoidable, especially for some of the older women who may have had the menopause many years before. However we sought to minimize this by not including women older than 60 years

\section{Conclusion}

The study of postmenopausal women using the MRS showed that the most common menopausal symptoms reported were in the somatic subscale; joint and muscular discomfort, physical and mental exhaustion and hot flushes and sweating. Regular physical activity and normal BMI were found to enhance QOL. Educational level, marital status, occupational status, parity and postmenopause duration were the most significant predictors of postmenopausal QOL.

Postmenopausal women should be assessed for postmenopausal symptoms using MRS by health care providers and help given to improve their QOL. Also, further research addressing women's health needs is also essential for improving the QOL of postmenopausal rural women.

\section{Acknowledgements}

We wish to thank all the women who participated in this study. We would also like to thank the authors of the original menopause rating scale version for the use of this instrument during this study.

\section{Funding: None.}

Competing interests: None declared.

\section{References}

1. Chen Y, Lin SQ, Wei Y, Gao HL, Wu ZL. Menopause specific quality of life satisfaction in community dwelling menopausal women in China. Gynecol Endocrinol. 2007;23:166-72.

2. Fallahzade H, Dehghani Tafti A, Dehghani Tafti M, Hoseini F, Hoseini H. Factors Affecting Quality of Life after Menopause in Women, Yazd 2008. J Shaheed Sadoughi Univ Med Sci. 2011:552-8.

3. Chedraui P, San Miguel G, Avila C. Quality of life impairment during female menopausal transition is related to personal and partner factors. Gynecol Endocrinol. 2009;25(2):130-5. 
4. Berecki-Giosolf J, Begum N, Dobson AJ. Symptoms reported by women in midlife: menopausal transition or aging? Menopause. 2009;16(5):1021-9.

5. Funmilola MO, Taiwo O. Experience of menopausal symptoms by women in an urban community in Ibadan, Nigeria. Menopause. 2009;16(4):822-30.

6. Al Dughaither A, Al Mutairy H, Al Ateeq M. Menopausal symptoms and quality of life among Saudi women visiting primary care clinics in Riyadh, Saudi Arabia. Int J Womens Health. 2015;7:645-53.

7. Sweed HS, Elawam AE, Nabeel AM, Mortagy K. Postmenopausal symptoms among Egyptian geripausal women. East Mediterr Health J. 2012;18:213-20.

8. Bairy L, Adiga S, Bhat P, Bhat R. Prevalence of menopausal symptoms and quality of life after menopause in women from South India. Aust N Z J Obstet Gynaecol. 2009;49(1):106-9.

9. Waidysakera H, Wijewardena K, Lindmark G, Naessen T. Menopausal symptoms and quality of life during the menopausal transition in Sri Lankan women. Menopause. 2009;16(1):16470 .

10. Nelson HD. Menopause. Lancet. 2008;371(9614):760770.

11. Poomalar GK, Arounassalame B. The quality of life during and after menopause among rural women. J Clin Diagn Res. 2013 Jan;7(1):135-9.

12. Ibrahim ZM, Sayed Ahmed WA, El-Hamid SA. Prevalence of menopausal related symptoms and their impact on quality of life among Egyptian women. Clin Exp Obstet Gynecol. 2015;42(2):161-7.

13. MRS - the Menopause Rating Scale [website] (http://www menopause-rating-scale.info/, accessed 25 April 2017).>

14. Research on the menopause in the 1990s. Report of a WHO Scientific Group. Geneva: World Health Organization; 1999 (WHO technical report series no. 866) (http://apps.who.int/ iris/bitstream/10665/41841/1/WHO_TRS_866.pdf, accessed 25 April 2017).

15. Gehad M, Samia A, Galila S. Effect of menopausal symptoms on women's quality of life in Benham city (Egypt) and Arar city (Kingdom of Saudi Arabia). Med J Cairo Univ. 2010;78(1):31930 .

16. Gold E. The timing of the age at which natural menopause occurs. Obstet Gynecol Clin North Am. 2011;38(3):425-40.

17. Heinemann L, DoMinh T, Strelow F, Gerbsch S, Schnitker J, Schneider H. The Menopause Rating Scale (MRS) as outcome measure for hormone treatment? A validation study. Health and Quality of Life Outcomes 2004, 2:67.

18. Chedraui P, San Miguel G, Avila C. Quality of life impairment during the female menopausal transition is related to personal and partner factors. Gynecol Endocrinol. 2009;25(2):130-5.

19. Mohamed H, Lamadah S, Al. Zamil L. Quality of life among menopausal women Int J Reprod Contracept Obstet Gynecol. 2014;3(3):552-61.

20. Elavsky S. Physical activity, menopause and quality of life: The role of affect and self-worth across time. Menopause. 2009;16:265-71.

21. Waidyasekera H, Wijewardena K, Lindmark G, Aessen T. Menopausal symptoms and quality of life during the menopausal transition in Sri Lankan women. Menopause. 2009;16:164-70.
22. Gharaibeh M, Al-Obeisat $S$, Hattab J. Severity of menopausal symptoms of Jordanian women. Climacteric. 2010;13(4):38594.

23. Mansikkamäki K, Raitanen J, Malila N, Sarkeala T, Männistö S, Fredman J, et al. Physical activity and menopause-related quality of life - a population-based cross-sectional study. Maturitas. 2015;80(1):69-74.

24. Skrzypulec V, Dabrowska J, Drosdzol A. The influence of physical activity level on climacteric symptoms in menopausal women. Climacteric. 2010;13:355-61.

25. Luoto R, Moilanen J, Heinonen R, Mikkola T, Raitanen J, Tomas $\mathrm{E}$, et al. Effect of aerobic training on hot flushes and quality of life - randomized controlled trial. Ann Med. 2012;44(6):616-26.

26. Tan M, Kartal M, Guldal D. The effect of physical activity and body mass index on menopausal symptoms in Turkish women: a cross-sectional study in primary care. BMC Womens Health. 2014;14(1):38.

27. Moilanen J, Aalto A, Raitanen J, Hemminki E, Aro A, Luoto R. Physical activity and change in quality of life during menopause -an 8-year follow-up study. Health Qual Life Outcomes. 2012;10:8.

28. Al-Musa H, Ahmed R, Alsamghan S, Abadi S, Alahmari S, Alshahrani $\mathrm{H}$, et al. The prevalence of symptoms experienced during menopause, influence of sociodemographic variables on symptoms and quality of life among women at Abha, Saudi Arabia. Biomedical Research. 2016;0976-1683.

29. Abedzadeh M, Taebi MM, Saberi F, Sadat Z. Quality of life and related factors in Menopausal women in Kashan city. Iran South Med J. 2009;12:81-8.

30. Charandabi S, Rezaei N, Hakimi S, Montazeri A, Taheri S, Taghinejad H, et al. Quality of life of postmenopausal women and their spouses: a community-based study. Iran Red Crescent Med J. 2015;17(3):e21599.

31. Lee MS, Kim JH, Park MS, Yang J, Ko YH, Ko SD, et al. Factors influencing the severity of menopause symptoms in Korean postmenopausal women. J Korean Med Sci. 2010;25(5):758-65.

32. Williams RE, Levine KB, Kaliliani L, Lewis J, Clark RV. Menopause-specific questionnaire assessment in US populationbased study shows a negative impact on health-related quality of life. Maturitas. 2009;62:153-9.

33. Shobeiri F, Jenabi E, Hazavehei SM, Roshanaei G. Quality of life in postmenopausal women in Iran: a population-based study. J Menopausal Med. 2016;22(1):31-8.

34. Abdullah B, Moize B, Ismail B, Zamri M, Nasir N. Prevalence of menopausal symptoms, its effect to quality of life among Malaysian women and their treatment seeking behavior. Med J Malaysia. 2017;72(2):94-9.

35. Dravta J, Real F, Schindler C, Ackermann-Liebrich U, Gerbase MW, Probst-Hensch NM, et al. Is age at menopause increasing across Europe? Results on age at menopause and determinants from two population-based studies. Menopause. 2009;16(2):385-94. 